\title{
Responses to warnings about the impact of eating disorders on fertility: A qualitative study
}

\section{Introduction}

Reproductive function is seen to be closely interwoven with nutrition and body weight (Key, Mason \& Bolton, 2000 p.98), and eating disorders (EDs) have commonly occurred in girls/ women during the peak years of their fertility (Morgan, 1999). As such, EDs have often been discussed in relation to reproductive health and as a risk to fertility. This is clearly the case with anorexia nervosa (AN), as the association between AN and 'subfertility' was embedded in its diagnostic criteria from 1994 (Morgan, 1999, p.168). After this time, the loss of periods (medically known as amenorrhea) was mandatory for a diagnosis of AN. Although this measure was subsequently removed from the DSM-5 (2013), the idea that starvation may effect fertility has structured a good deal of medical work in the field (Easter, Treasure \& Micali, 2011, Key, Mason \& Bolton, 2000, Mitchell \& Bulik, 2006), contributing to the belief that AN threatens reproductive capacity. In comparison, bulimia nervosa (BN) and eating disorder not otherwise specified (EDNOS) have been discussed less in relation to reproductive health, even though both can be associated with disruption to the menstrual cycle (Easter, Treasure and Micali, 2011).

The relationship between EDs and fertility has been discussed in terms of both short and long-term risks, but the empirical evidence in this regard is contradictory (Bulik et al, 1999; Easter et al, 2000; Katz \& Vollenhoven, 2000; Linna, Raeuori, Haukka, Suvisaari, Suiokas \& Gissler, 2013; Miltan, 2004; Mitchell \& Bulik, 2006). Given the extent to which AN is often framed as a risk to fertility, it may be surprising that there is a good deal of evidence which 
points to the contrary: although starvation can lead to the absence of menstruation in the short term, a number of studies suggest that a history of AN does not affect the ability to conceive in later life (Katz \& Vollenhoven, 2000, Key, Mason \& Bolton, 2000, Mitchell, 2006, Wentz, Gillberg, Gillberg, \& Rastam, 2005). Other studies have disagreed and indicated that EDs may indeed cause longer term reproductive issues, suggesting that women with a history of AN and BN may be more likely to present for fertility treatment (Linna et al, 2013), or take twice as long to conceive (Easter, Treasure and Micali, 2011). As this suggests, there is little agreement in the field, and the most frequent support for any kind of medical effect suggests that fertility is 'affected but not significantly compromised' (Easter et al, 2011, p.1496) in women with EDs. When situated in relation to the considerable data that fertility is not effected at all in later life, this at least suggests that the evidence on this matter is not clearcut.

But in terms of thinking about the relationship between fertility, medical risk and EDs, the veracity of the evidence is not necessarily the key (or only) issue. According to feminist work on EDs (Malson, 1998; Malson \& Ussher, 1996), as well as feminist scholarship on fertility/ infertility (Becker \& Nachtigall, 1992; Szewczuk, 2012), such concepts clearly have wider cultural and thus gendered meanings which are not adequately addressed within a biomedical framework. These observations emerge from wider feminist work on EDs which critiques biomedical discourses and their implications for understanding and treating of eating/body distress (Bordo, 1993, Holmes, 2016, Malson, 1998). In challenging the construction of EDs as individual pathologies, feminist work has examined how 'eating disorders' are actively constituted by medical discourse (Foucault, 1973), and in resisting a division between those who havel do not have EDs, feminist work positions EDs on a continuum with the discourses 
and practices of normative femininity (Bordo, 1993; Malson, 1998; Saukko, 2008). From this perspective, the meanings of fertility/ infertility, as well as related concepts such as menstruation/ amenorrhea, are always 'caught up in systems of meaning, symbolic representations and power relations' (Malson \& Ussher, 1996, p.509) in ways which cannot be reduced to medical 'complications'.

In positioning 'eating disorders' as medical constructions, feminist work is complimented by sociological approaches to health which work from the assumption that both health and medicine are socially produced. This is clear with sociological perspectives on medical risk which have long since insisted that risk warnings are articulations of social power (Herrick, 2009; Petrakaki, Waring \& Barber, 2014; Sachs, 1996). As with medicine more broadly, risks are not 'objective facts but are reflective of ... prevailing beliefs, values and cultures' [cf, Douglas, 1966] (Petrakaki, Waring \& Barber, 2014: 706). For example, in the case of fertility warnings and their location within the gendered construction of EDs, the risk discourse pivots on an assumed 'normative' desire for a child and an assumed horror at the prospect of involuntary childlessness - neither of which allow for the legitimate (but stigmatised) position of a woman deciding not to bear a child.

There has been considerable work on how medical risk is discursively constructed, and the importance of looking at how people negotiate such risks has long since been acknowledged (Sachs, 1996, p.649). Yet in terms of EDs and fertility, existing medical work is entirely quantitative in nature, paying no attention to issues of experience: how people with experience of an ED may be told about such risks, how they interpret them, and what impact (if any) they have on their relationship with an ED. As such, this study brings together feminist approaches to EDs and sociological studies of medical risk in order to illuminate 
how fertility warnings may be negotiated in practice. In drawing on data from 24 semistructured interviews with female participants, the article seeks to answer the following questions: 1) how do women with experience of $\mathrm{AN}, \mathrm{BN}$ and/or EDNOS respond to medical warnings about their fertility? What can such responses illuminate about the discursive operations (and implications) of medical risk within a specific context (that of EDs)? What do responses to fertility warnings suggest about the wider implications of medical approaches to EDs and their marginalisation of the social and cultural contexts of eating/ body distress?

\section{Risk, gender and eating disorders}

Although feminist work on EDs has examined how constructions of normative femininity are implicated within eating/body distress and - to a lesser extent - the medical paradigms used to treat EDs (Gremillion, 2003; Lester, 2001), there has been little work which centres the experiences of 'patients' in this regard, nor considers the area of fertility and risk warnings. As sociological work on risk has argued, constructions of risk invoke ideological narratives on causality, blame and responsibility, as seen explicitly in recent years with the neoliberal emphasis on 'personal responsibility' for health (Herrick, 2009; McClean, 2005). But ideas of both personality responsibility and blame are beset by problems and inconsistencies (Snelling, 2015), not least of all because they depoliticise the social contexts of health, and thus the ways in which identities are structured and lived within relations of social power (McClean, 2005). Such debates about blame and individual responsibility have been particularly prevalent with respect to another area of body 'management': obesity (Snelling, 2015). When compared to obesity, EDs such as AN and BN are now more likely to be cast in medical terms as mental illnesses or addictive behaviours, both of which complicate discourses of blame and 'free will' (Snelling, 2015: 7). Nevertheless, qualitative research on 
both medical and popular perceptions of EDs suggests that they do carry a kind of stigma. This is known as 'volitional stigma' - named as such because stigmatised perceptions of eating problems position them as form of wilful behaviour ('attention seeking', 'celebrity emulation' (Bannatyne \& Stapleton, 2015)), which thus implies both volition and 'choice'.

Such constructions are problematic and potentially disempowering for people living with EDs: they trivialise the complex aetiology of eating problems, whilst suggesting that they cannot be too bad if they are wilfully embraced. But this idea of 'choice' also immediately invokes the related concept of control, which has been widely discussed as central to understandings of AN in particular (Bordo, 1993; Malson, 1998). Within medical constructions of AN, the patient is paradoxically seen as 'exercising too much self-control' (Lawrence, 1979: 95) (a 'pathology' that is protected by duplicity, manipulation and 'disobedience' (Gremillion, 2003)), as well as being utterly 'out of control' - an individual who must be brought back into 'line' with 'normative' conceptions of eating/body weight and (as this article will explore), hegemonic conceptions of heterosexual femininity (Lester, 2001). But what is important here is that these constructions of control point to a paradox at the centre of the fertility warnings in relation to EDs: the delivery of risk information about health aims to ultimately prompt a change in the patient's behavior, thus assuming the possibility of 'informed choice' and reasoning (see Edwards, Elwyn, Covey, Matthews \& Pill, 1999). Yet in relation to EDs, the perceived need for this 'advice' pivots on the assumption that the patient is out of control and must therefore be shocked by the brutal 'truth' of medical 'fact' (as based on the conjecture 'who on earth would want to risk their own fertility?'). In addition, when situated in the context of work on both the sociology of illness and feminist approaches to EDs, it is important to recognise that an emphasis on 
“"choice" redirects blame for health outcomes' (Herrick, 2009: 57). This then focuses attention on the 'defective' individual themselves rather than, in this instance, the biomedical framework of much ED treatment which frequently fails to address the gendered contexts from which eating and body distress emerge (Gremillion, 2003; Holmes, 2016). A study of how woman in ED treatment negotiate fertility warnings can thus bring these spheres together, enabling a fuller understanding of how ED treatment may enact and enforce normative standards of femininity as a key 'criterion of health' (Lester, 2001, p.210), whilst illuminating the wider operations of 'risk' within a particular gendered and biomedical context.

\section{Methodology}

\section{Participants}

Ethical clearance for the project was granted by the University of East Anglia in May 2016, and participants were interviewed in May/June the same year (primarily via Skype or telephone). Recruitment for the study was undertaken via Beat: the UK's leading ED charity. Beat have a research page on which it is possible to advertise for participants, and they also circulate such calls on social media - avenues which ultimately recruited 20 participants for the study. A minority of participants (4) were then recruited via group mailing lists at the author's institution. In addition to being 18 or over, participants were eligible for inclusion in the study if they had experienced treatment for AN/BN/ Binge Eating Disorder (BED) or EDNOS. The decision was made not to restrict recruitment to participants with experience of AN in an effort to avoid wholly reinforcing the ways in which experiences of 'other' EDs have been marginalised within medical, feminist and qualitative research (Burns, 2004). As such, an additional aim of the study was to contribute new knowledge about the extent to 
which women with EDs other than AN are included within the discursive frameworks which link disordered eating with 'impaired' fertility.

Although the study was open to participants who identified as female/male/transgender, it recruited 24 female participants living in different regions of the UK, and recruitment ceased when it was considered that capturing more data would not produce new or different data (i.e. the same responses and issues were being reproduced in each interview). All of the participants had received a diagnosis of an ED, including AN (10), BN (5), EDNOS (3), AN $+\mathrm{BN}(3)$, atypical AN (1), AN +BN + EDNOS (1), and AN + BED (1). The ages of the participants ranged from 19-46, with a mean age of 26. In terms of ethnicity, participants identified as white British (19), white Scottish (1), white American (2), white Dutch (1), and British Asian (1). As this suggests, the study recruited a sample with a prominent white bias, unfortunately reflecting and consolidating the prevalence of white voices in ED research (Bezance \& Holliday, 2013, p. 357). A further bias was evident in terms of sexual orientation: with regard to the participants who felt willing (or able) to disclose this aspect of their identity, the majority identified as heterosexual (16), with the remaining participants identifying as bisexual (5) or lesbian/ queer (2).

Some participants considered themselves to be recovered from their ED whilst others did not, and they had collectively experienced a wide range of treatments (including in-patient and out-patient services, admissions to general hospital wards, various forms of therapy, and encounters with GPs). The aim of the research was not to examine the extent to which there is a causal link between eating disorders and fertility problems, but rather to explore how medical warnings about fertility are interpreted. In this regard, it was not necessary for participants to know whether they could conceive should they wish to. But as attitudes toward fertility and motherhood were discussed in the interviews, it is relevant to state here 
that one participant in the study had two children, and another was in the early stages of pregnancy. In terms of the information given in the interviews, none of the remaining participants had children or had tried to conceive.

It is also recognised here that the idea of a 'medical' or 'biomedical' approach to EDs implies a somewhat monolithic construct, and that such terms may encompass a range of different theoretical approaches and perspectives. Yet from the perspective of sociocultural/ feminist understandings, what is distinctive about biomedical perspectives is that they see EDs as 'biologically based serious mental illnesses' which are primarily conceptualised in individual terms (Levine and Smolak, 2014: 158). As Lock et al summarise with respect to AN, 'the medical view is that anorexia is an illness, and one that is identified with the person who has it...' (Lock et al, 2005: 321). But how this is actively translated into ED treatment practices and thus the treatment experienced by the participants in this study - is complex. For example, a great deal of clinical work focuses on the psychological (rather than strictly 'medical') aspects of EDs, albeit it with limited attention to sociocultural context (Holmes, 2017). These complexities are recognised here, but as the aspect of ED treatment under discussion specifically concerns itself with medical warnings about the body, referring to a contrast between medical and feminist approaches remains both useful and apt.

\section{Procedure}

Participants took part in a one-to-one semi-structured interview with the researcher/ author that lasted about one hour, and gave verbal consent for the interview to be recorded/ used for research purposes at the start. The interview schedule then covered key four areas including: 1) to what extent participants were told of potential risks to their fertility in treatment and 
how these risks were explained 2) how they felt about these perspectives, and their impact (if any) on their understanding of their ED 3) if participants had experienced disruption to their menstrual cycle and how they felt when this occurred/ resumed 4) if they felt that information about fertility risks should be part of treatment (and if so, how and when).

\section{Data analysis}

The interviews were recorded on a digital voice recorder and transcribed, and the participant data was anonymised at the point of writing. The data was then analysed using a discourseanalytic methodology which enables the researcher to attend to the ways in which identities or experiences are constituted in the interview transcript (Malson, Finn, Treasure, Clarke \& Anderson, 2004). As the interview transcripts frequently raised issues relating to femininity, gender norms and medical power, it was felt appropriate to draw upon feminist postructural work on EDs. In broad terms, this work has often explored the relationships between medical discourses on EDs and the subject positions adopted by female 'patients' (Boughtwood \& Halse, 2008; Malson et al, 2004). From this perspective, discourses are seen as actively constitutive of the reality of an ED (Potter \& Wetherell, 1987) in ways which produce experiences and identities within gendered relations of power (Foucault, 1973). Importantly, this position also acknowledges that whilst identities are socially constructed within discourse, the subject nonetheless exists as a 'social agent capable of resistance... produced

out of the clash between contradictory subject positions and practices' (Weedon, 1987, p.124). In the current study for example, the participants moved through multiple positions during the interviews in which they internalised, negotiated and often critiqued the medical frameworks under discussion. 
A thematic discourse analysis of the transcripts was conducted which involved three stages (Malson, Bailey, Clarke, Treasure, Anderson \& Kohn, 2011). Firstly, the transcripts were read and re-read to identify key themes. Second, the transcripts were coded using the themes emerging from the first stage: these were clearly shaped by - but did not simply map onto the focus of the interview questions, and were categorised as 'perspectives on fertility warnings and their relationship with questions of power'; 'attitudes toward menstruation' and 'attitudes toward motherhood'. The coded categories were then analysed in detail in order to explore how participants positioned themselves in relation to the warnings and the cultural contexts in which they were located, including normative constructions of femininity, and the biomedical frameworks of ED treatment.

My own identity as a woman who lived with AN for 20 years (see Holmes, 2016), who was warned about fertility risks numerous times, and who has invested in feminist approaches to EDs since recovery, inevitably shaped my position(s) in the dynamics of the interview encounter, as well as my analysis of the results. Indeed, feminist qualitative work does not deny that the self is always embedded in the structure, analysis and articulation of any research (Maynard and Purvis, 1994), and it is important to disclose this connection here. But to suggest that this renders my analysis 'biased' or 'distorted' is to shore up scientific (masculine) discourses on the possibility of 'objectivity' (Malson \& Ussher, 1996, p.510) - a perspective which has been critiqued by feminist research more broadly, as well as key feminist analyses of EDs (Bordo, 1993; Malson, 1998).

\section{Results and discussion}

Fertility warnings: communication and power 
All of the participants were told verbally that an ED may compromise fertility within the context of treatment, aside from one who had only come across such perspectives on the internet. Participants were informed about such risks by a range of healthcare professionals including GPs, psychiatrists, nurses, support workers, counsellors and therapists. As might be predicted from the existing literature, participants with experience of AN were warned more frequently than those with other types of ED. So as one participant with experience of BN suggested, "maybe it is just a doctor tick box exercise like "bulimia = lower risk of fertility problems"" (P5). This is indicative of the extent to which AN has been forgrounded in conceptions of fertility risk (perhaps due to the primacy placed on a low BMI), even though other EDs can also disrupt the menstrual cycle (Wolfe, 2005). Participants with experience of AN were warned to differing degrees (some many times and some once or twice), and they expressed such comments as 'They kind of drilled it home quite a lot... They didn't let me forget the ... medical impact that $[\mathrm{AN}]$... could have on me' (P3).

In terms of the content of the warnings, participants received different medical information. Some participants (6) were clearly told that the risk was short-term. But a majority of the participants (17) described how they were also warned of long-term implications. As one explained: 'Yeah, it was sort of like, you might or you might not [have problems] - it is left just hanging over you' (P17). Although this might well reflect the contradictory evidence at play in the field, this lack of clarity was often perceived to be deliberate - part of a punitive and manipulative strategy intended to change the patient's behaviour. When asked about how the warnings made them feel, one participant explained how:

It was like always unclear, and it did used to annoy me because I would think 'you can't say that [about my future fertility]... I can tell that you're just trying to 
scare me or trying to like dominate me... and that's not the way to get me to be better' (P9).

Research on the communication of medical risk has been attentive to the power dynamics in such encounters in which shame, guilt, shock and fear might be used to effect behavioural change (Ruiter, Abraham \& Kok, 2001). Indeed, the warnings were regularly spoken about by the participants as 'threats' (P18), 'blackmail' (P3, P15, P23), 'shock tactics' (P18, P24) and 'scaremongering' (P15). In supporting findings from wider feminist analyses of ED treatment (Boughtwood \& Halse, 2008; Gremillion, 2003), these terms suggest a conception of treatment as a site of conflict or battle which unfolds within unequal relations of power: it is the health professionals who are seen as being in a position to 'scare', 'threaten' or 'blackmail'. The participants were clearly able to critique and question such dynamics (at least in the context of the interview), so they are far from 'passive' subjects here. But the responses make clear how they felt that they were the recipients of threats, and how they saw the warnings as essentially manipulative strategies intended to change their behaviour.

Only one participant felt that fears surrounding fertility (and the warnings relating to this) were an impetus behind her drive to pursue recovery (P14). Others oscillated between suggesting that they felt impervious to the warnings, to offering critiques of why the messages were unhelpful at the time. As one participant with experience of AN explained when answering the same question as above:

I always used to say to them like 'you can stop going on about not having periods, I do realise that this can cause infertility ... and effect my future choices' ...[But]... I just remember thinking that 'this is the least of my worries. My worry is the 30 grams of cashew nuts that you are going to make me eat this afternoon!' 
[laughs]... You can't even make sense of a carrot stick at your lowest - never mind whether you want children... It wasn't really helpful, nor an incentive to get better (P10).

The participant appears to accept premise that having an ED may compromise her fertility, and she presents this as an 'obvious' (if irritating) medical 'truth'. But she also foregrounds how an emphasis on this during the most active stage of self-starvation was ill-timed. Other participants felt that the temporality of the warnings was inappropriate and insensitive in relation to their immediate experience (the idea of the pregnant body was overwhelming as getting 'fat' was their biggest terror at the time), whilst others still felt that the warnings were misplaced due to their age: they were teenagers, and not remotely interested in bearing a child. This indicates the temporal complexity of the warnings and their contradictory approach to effecting 'compliance behaviours' (Edwards et al, 1999): they are intended to stop the individual engaging in 'disordered' eating in the here and now, but the main incentive for this is the possibility of 'disrupting' an absence - a potential future life event which may have little relevance for the patient at the time.

This idea of a mismatch between medical discourses and experiences of eating/body distress was further articulated by participants who felt that the warnings increased feelings of isolation, helplessness and self-blame. As a participant with experience of atypical $\mathrm{AN}^{\mathrm{i}}$ explained in talking about how the warnings made her feel:

The warnings made me feel helpless. They seemed to ignore that I would already be eating if I could. I know what I'm doing. I know it's stupid. I know like it ruins my mental health and my physical health, so if it was as easy as just picking up a sandwich I would. ... For someone to say if you don't eat now you'll never 
have children is not helpful at all. That is just worrying and stressful and probably makes things worse... It just adds to the things that I'm fucking up ... or that go wrong when I do this... (P4).

This relates back to discussions of both choice and control, and their complex imbrication within both risk warnings and ED experience. On one level, the participant constructs herself as an active agent who is in control ('I know what I'm doing'), whilst she simultaneously suggests that she is powerless to challenge the behaviours she describes. This complexity is then positioned as sitting uncomfortably with the 'choice' implied by the warning ('if it was as easy as just picking up a sandwich I would'), and crucially indicates how (perceived) agency fosters blame (Snelling, 2015: 7). Indeed, the last part of the response lends itself to the suggestion of self-blame ('the things that I'm fucking up'). Crucially, the response makes clear how such cautions frame health as the outcome of personal choices (McClean, 2005), bolstering the individualistic focus of both medical risk warnings and ED treatment.

\section{Menstruation, amenorrhea and constructions of femininity}

As discussed in the framing of the article, feminist approaches to EDs are critical of the extent to which medical models locate such problems within the individual, rather than the gendered cultural contexts that help to engender eating and body distress. The constructions of femininity implicated within both EDs and fertility warnings came into view around two particular themes in the data: attitudes toward the presence/absence of menstruation, and assumptions about the desire to bear a child. These themes are discussed consecutively in the following two sections.

Because the study was seeking to understand whether/ how the warnings impacted upon the women's understanding of, or feelings about, their ED, it was important to explore how they 
felt about the actual or literal possibility of amenorrhea. As the "'amenorrhea-ic" body is inevitably construed in relation to those discourses and discursive practices that surround menstruation' (Malson, 1998, p. 116), participants were asked to recall the feelings associated with their first period. As in Malson and Ussher's (1996) analysis of how women diagnosed with AN negotiate menstruation/amenorrhea, first experiences of menstruation were framed as 'dirty', 'disgusting' and 'messy', and participant talk invoked a Cartesian dualism in which the female body threatened to overwhelm and escape the control of the mind (Malson \& Ussher, 1996, p. 513). As one explained: I think it's just like, my body was sort of ... somewhere where my mind wasn't? My body was becoming like a woman, but inside, in my head, I still felt like a child' (P19).

Within psychological perspectives on EDs, such responses have been interpreted as offering 'aberrant' or 'maladaptive' attitudes toward the adoption of adult femininity (Malson \& Ussher, 1996). But they can also be read as responses to dominant cultural discourses surrounding menstruation which 'constitute... and regulate... the menstruating female body as a ... signifier of unwanted femininity' for all women (Malson \& Ussher, 1996, p. 512). Furthermore, rather than a rejection of femininity per se, the women's talk - which used terms such as 'disgusting' and 'messy' and framed the body as overwhelming/ overtaking the mind - can be seen as refusing denigrating constructions in which menstruation epitomises femininity as abjection, 'an excess of flesh and body fluids that disgusts and repels' (Fournier, 2002, p.63).

Conversely, in terms of those who had experienced disruption to their menstrual cycle (19), the loss of periods was spoken about in overwhelmingly positive terms. Some described it as signalling the erasure of 'unwanted femininity' (Malson \& Ussher, 1996: 512), as in the case 
of one participant who recalled how periods epitomised her 'abhorrence about being a woman' (P23). Rather than worrying about the loss of periods, participants often used menstruation as a physical yardstick to measure how (well) their ED was progressing:

As long as you haven't got [periods]... it's proof that you're underweight ... I hate saying that ... like I hate admitting that, but it's kind of true. It reassures you that you are in control and underweight. I think that maybe if your periods start again it's like confirmation that you are OK - it's weird isn't it? I think it's because it is often used as a gauge of severity ... [original emphasis]' (P9).

Whilst the medical warnings try to 'scare' the participants with the fear that their reproductive bodies (and lives) may become out of their control (i.e. they might not 'work' in the future), this participant articulates the 'amenorrhea-ic' body as precisely signifying selfcontrol. On one level, she distances herself from the perceived mind-set of the ED ('I hate saying that... 'It's weird isn't it?') in order to justify this seemingly 'deviant' attitude toward menstruation. In calling herself 'weird', she momentarily pathologises herself, bolstering a medical perspective that rejects the possibility of an active desire for amenorrhea (as opposed to horror at the risk of infertility). But on another level, her response also turns the focus and the reason for the 'weird' thinking - back on the framework of medical treatment itself which, for many participants, frequently demanded intimate knowledge about their menstrual cycle. Indeed, amenorrhea may have been removed from the diagnostic criteria for AN, but some participants spoke of how they strove to 'fit' or 'tick off' what they saw as this still pervasive measure (P8, P10, P23, P24). This is indicative of the ways in which the experience of an ED is actively constituted by medical discourses and practices, rather than simply treated by them (Gremillion, 2003, Malson et al, 2004). 
But this disjuncture between clinician and patient in terms of what is being valued here (the perceived importance of resuming menstruation versus the active desire to cause amenorrhea), is also revealing in thinking about the contradictory cultural discourses which regulate western femininity, and in which EDs are often enmeshed. In their discussion of treatment for AN, Boughtwood and Halse refer to the disjuncture between 'medical' and 'cultural' conceptions of the body: whilst society may position thin bodies as attractive and 'healthy', medicine 'continuously attempts to educate girls about what starvation does to the body', using 'technologies like BMI [Body Mass Index] and bone scans to assert the legitimacy of biomedical discourse, claiming bodies must have enough fat to be deemed healthy' (2008, p.275). After all, in the warnings about the need for the women to protect their fertility, there is no trace of the pervasive value that society places on very slim women, and the aspirational cultural values (success, control, restraint) that are signified by such bodies (see Bordo, 1993). Indeed, the responses offered by the women in this study, particularly with respect to menstruation/ amenorrhea, belie this (impossible) bid to position the fertile female body as simply a 'factual', 'healthy' norm - mapped out by medical criteria. Instead, and as has been discussed, the participant talk often attested to the ways in which the menstruating female body is coded in terms of 'monstrosity' and 'excess' in patriarchal culture - repeatedly using terms such as 'crazy', 'dirty', 'filthy', 'fat' and 'overwhelming'.

In her discussion of AN, Fournier (2002) discusses the particular significance of such discourses to female self-starvation. According to Fournier, AN epitomises the struggle between the idea of woman as effacement and absence (not really there) versus the reduction of woman to her body (so that her presence is reduced to nothing but flesh) (2002, p. 56). Along with other feminist scholars, Fournier frames self-starvation as a means of 'cutting 
out' or away the 'excesses of female flesh', and the replacement of this with nothingness, invisibility and 'purity’ (2002, p.66) (see also Malson, 1998; Malson, 2009). Women’s reproductive capacities may hold a particular significance within this abhorring image of femininity as they can be 'inscribed within patriarchal discourse as excessive - a feminine (discursive-material) excess signified by women's body fat' (Malson, 1997 p.238). This reduction of the female body to a mass of (fat) flesh is implicit in the account offered by one participant when she explained how her periods resumed after taking the pill:

I'm glad [the period]... was chemical otherwise I would have been like "oh well I guess I crossed that threshold into being fat enough!” Like flesh, fertility - all of it - it would have been too much... so overwhelming to me (P24).

In this regard, there is a clear paradox at the root of the warnings about amenorrhea. On one level, they try to make patients aware of the threat their actions pose to 'healthy', fertile femininity, which requires a certain level of body fat. But EDs are also implicated within cultural norms surrounding femininity that value effacement and fragility, and abhor the fleshy, menstruating woman. If the warnings about fertility are seen as both upsetting and ineffective, it may be in part because they seek to 'sell' (back to) women an image of femininity from which they have already been alienated.

\section{Imagining/ resisting maternal futures}

The last section examined how the warnings were discussed by the participants in ways which attest to their enmeshment within particular constructions of feminine identity and embodiment. But recognition of the gendered implications of the warnings was most clear in the discussions of motherhood. In exploring this theme, this section also returns to the significance of thinking about the warnings as 'scare' tactics and 'fear appeals' (Ruiter, 
Abraham \& Kok, 2001). This is particularly so in terms of the risk frameworks assuming the inevitability of heterosexual, maternal femininity, whilst simultaneously abstracting the warning (and thus the person) from the gendered contexts in which eating problems may emerge.

Out of the 22 women in the sample who did not have children and who were not pregnant, 6 felt sure that they did not want children in the future, 6 were ambivalent, and 10 felt that they did. In terms of the latter group, participants made such comments as 'I will be absolutely devastated if I can't ... conceive' (P7), or simply 'Well I've always wanted children' (P4). But this still leaves 12 participants in the study who did not firmly see themselves as future mothers at this time. In situating this admittedly small sample within its wider social and historical context, statistics on the number of women without children in the UK are often variable (and it is difficult to distinguish between women who are voluntarily childless from those who are not) (Gillespie, 2000). But it is a social trend that is seen to be on the rise, due to more diverse family configurations, wider lifestyle shifts and women's increased participation in paid employment (Gillespie, 2000). Indeed, the participants who rejected/ were unsure about the idea of becoming a mother often associated the role with containment, a lack of agency, and less freedom to achieve in (or even have) a career. Given that up to half of the study sample were either sure that they did not want a child, or were at the very least ambivalent about the possibility, this raises crucial questions about how an ED itself may be bound up with a resistance to the discourses which constitute normative femininities - a theme that has been widely discussed in feminist work (Bordo, 1993; Holmes, 2016; Lester, 2001; Malson, 1998).

For example, a 20 year old participant with experience of AN and BED outlined how she saw normative constructions of femininity as deeply intertwined with her eating/body distress: 
I've always hated the formulation of the stereotypical girl and woman. Because of the idea of stay at home mums and having kids and everything like that ... And because I didn't want that, it was another thing feeding into the idea that something was wrong with me ... I went through a big time ... of not wanting kids and was ashamed of that fact. Because these expectations were everywhere in treatment, and mentioned by friends and family, I didn't talk about these feelings, even though they are probably one of the main reasons I got ill in the first place ... (P15).

This participant, along with others in the study, clearly places the medical discourses of treatment on a continuum with wider cultural constructions of womanhood which still centre on motherhood as a 'natural' and 'inevitable' part of femininity (Gillespie, 2000: 229). In doing so, she highlights how the pervasive nature of the expectations - including those in medical warnings - actively contributed to her silencing, because they struck at the core of why she may have developed eating problems in the first place.

The possibility of fertility warnings exacerbating the stronghold of the ED is also suggested in the following response from a participant who explicitly felt that her problems emerged because she was 'rejecting certain gender ideas' (P1). Now 46, the participant described how her response to the threat of impaired fertility was always 'OK great!':

$[\mathrm{T}]$ hey are just assuming that you want [children], and if you don't want them ... or internally you have a sense that you are doing this because you are rejecting certain gender ideas.... then the idea of actually being able to control the one thing that women do - or that you're not a real women if you don't do [laughs] - 
would be absolutely amazing. I think such a warning ... is quite an incentive [original emphasis] (P1).

In this regard, the normative assumptions contained in the risk warning - pivoting on the idea that infertility will be a horrifying 'disruption' of a woman's life course - have potentially damaging implications. If the development of eating/body distress is bound up with the pressure and power of normative femininity, warnings which seek to beckon individuals back to such norms may be harmful (both psychologically and physically). This was already demonstrated with respect to the discussion of menstruation/ amenorrhea. But it is articulated even more explicitly in the responses above, and in the highly ambivalent responses to motherhood offered by some of the participants.

Although such participants found the risk warnings variously damaging and problematic, there is also more to these cautions than making erroneous assumptions about the desire to become a mother. When viewed from another perspective, the indiscriminate bid to warn the female patient suggests a clear presumption that this is a sensitive - and thus potentially hurtful - issue, and for most of the women in the study it was (regardless of their future aspirations). As a result, we are left with the impression that this aspect of treatment seeks to scare women into changing their eating behaviour by reaching for what is assumed to be an area of vulnerability - ripe for 'wounding' and shaming. As such, this dynamic can be seen as offering a vivid dramatisation of how 'work of gender inscription hurts' - involving symbolic violence, wounding, and (real) pain (Fournier, 2002: 68).

The fact that many of the participants 'called out' such strategies does not mean that they were not received as both powerful and painful: indeed, it was clear across the interviews that there was something of a desire to 'hit back' at such verbal arrows as a way of redressing the 
power balance. As such, even the participants who were keen to bear a child in the future were often critical of the expectations which structured the warnings. The interview responses also belied the suggestion (as implied in the risk warning) that women need to protect their reproductive capacity in order to have life 'choices' in the future. For example, the discussions of the assumptions contained in the warnings led to exchanges about how society viewed women who were childless by choice. As one participant who was currently ambivalent about the prospect of having a child explained: 'People just like really struggle that I'm not like maternal straightaway... "you need to have them before you are 30 ” ... It is very stigmatised still - like "why aren't you wanting them?"” (P4). This participant emphasises how being childless by choice is a stigmatised form of female identity (Gillespie, 2000) - a stigma that is upheld and confirmed by the warnings themselves.

Although the medical warnings imply that the women need to eat 'properly' so that they will retain control over their reproductive capacities (for the future), the idea of 'free choice' in relation to childbearing has often been critiqued by feminist scholars. As Earle and Letherby explain, despite claims that women have 'increasing and considerable control over reproduction (in the West at least), in reality, there are many interrelated factors that mitigate against this...' (Earle and Letherby, 2007, p.234) - including the pressure of societal expectations, as well as medical discourses on female fertility. For example, the women in the study frequently invoked the socio-biological project of the biological clock (Friese, Becker \& Nachtigall, 2006) in describing their fertility plans:

I ... think there a lot of messages in the media about fertility ... like if you don't have a baby by the time you are 35 you'll never have one... It's the combination of that message and like knowing my history that makes me think I should probably think about this seriously sooner rather than later... (P5). 
This shows that 'scare' tactics surrounding fertility and EDs again cannot be separated from wider social and cultural norms about female reproduction. In fact the quote makes clear how EDs, and the idea of the biological clock, operate as discourses through which women can be 'blamed' for infertility - again fostering an individualising perspective which takes no account of the gendered social contexts in which these 'problems' emerge (Friese, Becker \& Nachtigall, 2006).

Furthermore, it is revealing here that resistance toward motherhood coalesced in some responses (and experiences of treatment) with the idea of the ED identity, thus being framed as part of the 'pathology' itself. Both forms of subjectivity are cast in terms of ambivalence about transitioning into normative 'adult' femininity, and both are often positioned as childlike and not yet fully mature. As Rosemary Gillespie summarises, women who are childless by choice are often posited as 'future mothers, who [will] ... change their minds with the onset of maturity...' (2000, p. 228), whilst women with EDs are often constructed as seeking to stave off womanhood proper (Malson, 1998; Saukko, 2008). The participants in the study frequently spoke of how medical professionals, therapists, as well a family and friends, insisted that there would be a 'change of mind' about having a child. As one participant recalled in explaining responses she had encountered: 'oh well I expect you will change your mind and have children at some point' (P6). But this discursive manoeuvre negates the choice to be childless, and thus leaves normative constructions of maternal femininity intact (Gillespie, 2000). Indeed, based on the evidence here, there is a potential danger that perfectly legitimate life choices (such as woman deciding not to have a child) might be framed as part of ED 'pathology', and its apparent 'interruption' of a 'normative' 
female path. Furthermore, it is precisely a risk formulation, in which it is assumed that taking your fertility 'seriously' and wanting to bear a child is equated with optimum wellness and normality, which makes this worrying conflation possible.

\section{Conclusion}

This study has sought to consider how women with experience of an ED respond to risk warnings about fertility. In so doing, it has aimed to contribute to understandings of the ideological operation of risk warnings; insight into how such discourses may be 'used' and negotiated; and feminist critiques of ED treatment.

In terms of contributing to sociological understandings of health and risk, the responses here highlight the problematic implications of risk discourses on a number of different levels. First, the study confirms the long history of work which suggests that risk warnings are fundamentally ideological and thus bound up with relations of power - in this case, normative ideas about what constitutes 'healthy' femininity. This clearly questions the conceit that, in terms of health warnings, patients are simply being given the 'facts' in order to make the 'right' choices about their health. These are only the 'right' choices in so far as they endorse cultural norms about heterosexual femininity that are presented to patients as 'common sense'. Second, the emphasis on EDs clearly demonstrates how this dynamic necessarily pivots on individualised conceptions of health which are abstracted from social and cultural contexts. Although such individualised discourses are not new in terms of biomedical medical conceptions of health and illness, their currency has been bolstered by ideological trends in neoliberalism which yoke health firmly to notions of 'personal responsibility' and accountability (Herrick, 2009; McClean, 2005). This study demonstrates why it is so vital to critique such discourses. They not only 'depoliticise' the social contexts 
of ill health (McClean, 2005: 633) and thus obscure the operations and implications of inequality and oppression: they also effectively 'blame' patients for their own subjugation and suffering which - it is implied - is in their gift to end. This has particular implications for EDs which, as discussed in the framing of this article, are complexly constructed (and stigmatised) around discourses of will, 'choice' and control, with 'patients' often seen as being both over-controlling and 'out of control'. If 'patients' feel that they are being judged, blamed and stigmatised, this may hinder help-seeking and the efficacy of treatment itself - as work on stigma and EDs has shown (Bannatyne and Stapleton, 2015).

Indeed, whilst it is important to think about the broader issues this study raises for sociological approaches to risk warnings, the research also foregrounds how the construction and implication of the warning is context specific. In this regard, a specificity of the risk warnings around EDs and fertility may be that they actively invoke (some of the) discourses that are implicated within the 'illness' itself - effectively pouring petrol onto fire. In this regard, the study clearly confirms feminist arguments about how biomedical approaches to EDs abstract eating/body distress from cultural constructions of gender - with potentially grave consequences. For some of the participants, the fertility warnings actively affirmed different expressions of femininity as 'deviant', 'aberrant' or 'unfeminine' (Gillespie, 2002, p. 225), and further encouraged them to pursue the ED as a potential escape from normative gender ideals. At best, the warnings are seen as making problematic assumptions about the aspirations of the female patients, which may curtail feelings of agency and choice. At worst, they may push women further into destructive bodily and eating practices, and silence the distress that may be articulated by an ED. In seeking to beckon women back to normative constructions of femininity (fertility, menstruation, motherhood), the responses in this study appear to confirm the argument that the discourses which precipitate eating disorders and the discourses that explain and treat them 'move in a vicious circle', affirming 'similar historical 
[and] social ideals that account...for women's excruciating attempts to conquer their gender' in the first place (Saukko, 2008, p.3). In terms of EDs, the responses compel us to revisit debates about the status of medicine as a social construct which unfolds within relations of social power and to listen to women's views about the treatment practices that are 'allegedly helping them' (Saukko, 2008: 43).

The case study of EDs here also raises broader issues about the potentially paradoxical nature of the individualising discourses of medical risk and their implications for how 'patients' are conceptualised and treated. In seeking to frame and foreground risk, medicine locates the problem in the individual (abstracted from any social context), but then proceeds to treat everyone the same. So in the case of fertility warnings and EDs, we see no real attention to individual biography, identity and aspiration: all of the women are assumed to be heterosexual, and as harbouring a 'natural' desire to bear a child. The idea that medicine is highly normative - assuming and perpetuating normative conceptions of femininity - has long since been recognised by feminist work. But the research discussed here suggests that such strictures may be particularly acute for women with EDs: not only may normative conceptions of femininity underpin and shape the aetiology of an ED, but the aspects of treatment dealt with here may actively prohibit the exploration of alternative possibilities for self-identity.

In comparison, feminist conceptions of health could actually be seen as less attentive to the individual, in so far as they locate the 'problem' in society and culture. But as this study has aimed to demonstrate, feminist approaches do not deny the specificity (nor agency) of the individual, but are interested in the 'role of social structural factors in shaping individual's experiences [my emphasis]' (Piran, 2010: 187), or 'the distinctive denotation of gender in 
each person's experience [my emphasis]' (Zerbe Enns 1993: 17). In this regard, feminist approaches (in both research and practice) have the potential to be more sensitive to how individuals negotiate scripts of identity, exploring the interplay between the individual and the social.

Overall, this study strongly confirms feminist arguments that ED treatment practices, as well as models of 'recovery', are structured around dominant standards of femininity, forcing women into a 'corseted model of femininity regardless of how tight the fit' (Lester, 2001, p.210). Fertility warnings may well sit at the apex of such constructions, effectively offering an acute dramatisation of their concerns. But the idea of a 'tight fit' also implies something about the reception or experience of being treated within these frameworks, again suggesting the importance of looking at how warnings are negotiated. Many of the findings in this study are based on the women actively reflecting on their own social construction as 'eating disordered' subjects (and 'disordered' women), and critiquing the terms on which this operates. Whilst they sometimes spoke from a position which internalised or naturalised medical norms (and thus accepted discourses of 'pathology' and 'risk'), they also challenged the beliefs, values and language used to construct their identities within treatment contexts. A feminist postructural position suggests that 'calling into question or deconstructing one's experience can lead to possibilities for change and empowerment' (Aston, Price, Kirk \& Penney, 2012: 1187). But it should be noted here that these critiques have been articulated after the fact and outside of treatment - an arena not often engaged with the politics (nor the evidence) emerging from feminist qualitative research

The responses to the fertility warnings were strikingly consistent, but it is acknowledged here that the generalizability of the results is limited: the sample size is relatively small (24), and 
is dominated by white, predominantly heterosexual, women (limiting the extent to which discourses of intersectionality could be fully explored). In addition, studies involving male participants would clearly provide a useful comparison, particularly given that $\mathrm{AN}$ has been seen to effect testosterone levels in boys/men (Key, Mason \& Bolton, 2000, p.104). It is also acknowledged here that fertility warnings do not represent treatment approaches in their entirety, and that constructions of AN predominate in this study - not only in terms of the participants, but also the medical discourses being explored. Finally, it is stated here that the author's own long-term experience of AN shaped the drive to pursue this project, as well as the analysis of its results and that - in terms of ambivalent responses to fertility warnings she is proud to add her voice to the women's views which are represented here.

\section{Acknowledgements:}

With thanks to all the participants who took part in this study and shared their experience. With thanks to Sanna Inthorn and the anonymous reviewers for their helpful comments on this article.

\section{Works cited}

- American Psychiatric Association. (2013). Diagnostic and statistical manual of mental disorders (5th ed.). Arlington, VA: American Psychiatric Publishing. 
- $\quad$ Aston, M, Price, S, Kirk, SFL \& Penney, T. (2011). More than meets the eye.

Feminist postructuralism as a lens toward understanding obesity. Journal of Advanced Nursing, 24: 1187-1194: doi: 10.1111/j.1365-2648.2011.05866.x

- Bannatyne, A, Stapleton, P. (2015). Educating Medical Students About Anorexia Nervosa: A Potential Method for Reducing the Volitional Stigma Associated with the Disorder, Eating Disorders, 23: 115-133: doi: 10.1080/10640266.2014.976102.

- Bezance, J, Holliday, J. (2013). Adolescents with Anorexia Nervosa have their say: a review of qualitative studies on treatment and recovery from anorexia, European Eating Disorders Review, 21, 352-360: doi: 10.1002/erv.2239.

- Bordo, S. (1993). Unbearable Weight: Feminism, Western Culture and the Body. London and California: University of California Press.

- Boughtwood, D., \& Halse, C. (2008). Ambivalent appetites: dissonances in social and medical constructions of anorexia nervosa, Journal of Community and Applied Social Psychology, 18, 269-281: doi: 10.1002/casp.923

- Bulik, C.M, Sullivan, P.F, Fear, J.L, Pickering, A, Fear, Dawn, A, \& McCullin, M. (1999). Fertility and reproduction in women with anorexia nervosa, J Clin Psychiatry, 60: 130-5. http://www.ncbi.nlm.nih.gov/pubmed/10084645

- Burns, M. (2004). Eating like an Ox: Femininity and Dualistic Constructions of Bulimia and Anorexia. Feminism and Psychology, 14 (2), 269-295. doi: 10.1177/0959353504042182.

- Crow, S.J, Thuras, P, Keel, P.K, \& Mitchel, J.E. (2002). Long-term menstrual and reproductive functions in patients with bulimia nervosa. Am J Psychiatry, 159: 104850. 
- Douglas, M. (1966). Purity and Danger: an analysis of the concepts of pollution and taboo, London: Routledge and Kegan Paul.

- Douglas, M. (1992). Risk and Blame: Essays in Cultural Theory: London and New York: Routledge.

- Earle, S \& Letherby, G. (2007). Conceiving Time? Women who do or do not conceive, Sociology of Health and Illness, 29: 233-250. doi: 10.111/j.4679566.2007.00546.x

- Easter, A, Treasure, J \& Micali, N (2011). Fertility and prenatal attitudes towards pregnancy in women with eating disorders: results from the Avon Longitudinal Study of Parents and Children An International Journal of Obstetrics and Gynaecology, 118, 1491-1498. doi: 10.1111/j.1471-0528.2011.03077

- Edwards, A, Elwyn, G, Covey, J, Matthews, E \& Pill. R. (2001). Presenting risk information: a review of the effects of 'framing' and other manipulations on patient outcomes, Journal of Health Communication, 6, 61-82. doi:.10.1080/10810730150501413

- Foucault, M. (1973). The Birth of the Clinic: An Archaeology of Medical Perception, New York: Pantheon Books.

- Fournier, V. (2002). Fleshing out Gender: Crafting Gender Identity on Women's Bodies, Body and Society, 8 (2): 55-77.

- Friese, C, Becker, G \& Nachtigall, R.D. (2006). Rethinking the biological clock: Eleventh-hour moms, miracle moms and meanings of age-related fertility, Social Science and Medicine, 63: 1550-1560. doi: 10.1016/j.socsimed.2006.03.034 
- Gillespie, R. (2000). When no means no: Disbelief, disregard and deviance as sources of voluntary childlessness, Women's Studies International Forum, 23, 223-234. doi: $10.1016 / \mathrm{S} 0277-5395(00) 00076-5$

- Gremillion, H. (2003). Feeding Anorexia: Gender and Power at a Treatment Center, Durham and London: Duke UP.

- Herrick, C. (2008) Shifting blame/ selling health: corporate social responsibility in the age of obesity, Sociology of Health and Illness, 31: 51-65. doi: 10.1111/j.14679566.2008.01121.x

- Holmes, Su. (2016). 'Blindness to the obvious?': Treatment experiences and feminist approaches to eating disorders, Feminism and Psychology. Published online before print July 7, 2016, doi: 10.1177/0959353516654503.

- Holmes, Su. (2017). The role of sociocultural perspectives in eating disorder treatment: A study of health professionals, Health: An Interdisciplinary Journal for the Social Study of Health, Illness and Medicine, online first, 23 June, http://journals.sagepub.com/doi/full/10.1177/1363459317715778

- Katz, M.G \& Vollenhoven, B. (2000). The reproductive endocrine consequences of Anorexia Nervosa, British journal of Obstetrics and gynaecology, 107, 707-713. doi: 10.1111/j.1471-0528.2000.tb13329.x

- Key, A, Mason, H and Bolton, J. (2000). Reproduction and Eating Disorders: A fruitless union, European Eating Disorders Review, 8 (2): 98-107. doi: 10.1002/(SICI)1099-0968(200003)

- Lawrence, M. (1979). Anorexia Nervosa - The Control Paradox, Women's Studies International Quarterly, 2: 93-101. 
- Levine, M. P \& Smolak, L. (2014). Paradigm clash in the field of eating disorders: a critical examination of the biopsychiatric model from a sociocultural perspective, Advances in Eating Disorders, 158-170. DOI: http://dx.doi.org/10.1080/21662630.2013.839202

- Lester, R. (2001). Like a Natural Woman: Celibacy and the Embodied Self in Anorexia Nervosa. In E.J Sobo \& S. Bell (Eds), Celibacy, Culture and Society: the anthropology of sexual abstinence (pp.197-213), Madison: University of Wisconsin Press,

- Linna, M.S, Raeuori, A, Haukka, J, Suvisaari, J, Suiokas, J \& Gissler, M. (2013). Reproductive Health Outcomes in Eating Disorders, International Journal of Eating Disorders, 46: doi: 10.1002/eat.22179.

- Lock, A, Epston, D, Maisel, R \& de Faria, N. (2005). Resisting anorexia/bulimia: Foucauldian perspectives in narrative therapy, British Journal of Guidance \& Counselling, 33, doi.org/10.1080/03069880500179459

- Malson, H. (1997) Anorexic bodies and the discursive production of feminine excess. In Jane. M. Ussher (Eds), Body Talk: The Material and Discursive Regulation of Sexuality, Madness and Reproduction (pp.223-245), London: Routledge.

- Malson, H. (1998). The Thin Woman: Feminism, post-structuralism and the social psychology of anorexia nervosa. London: Routledge.

- Malson, H. (2009). Appearing to disappear: Postmodern Femininities and self-starved subjectivities. In H. Malson, and M. Burns (Eds), Critical Feminist Approaches to eating dis/orders, (pp.135-145), Sussex: Routledge. 
- Malson, H, Ussher, J.M. (1996). Bloody women: a Discourse Analysis of Amenorrhea as a Symptom of Anorexia Nervosa, Feminism and Psychology, 6, 505521. doi: $10.1177 / 0959353596064003$

- Malson, H, Finn, D.M, Treasure, J, Clarke, S, \& Anderson, G. (2004). Constructing 'The Eating Disordered Patient': A Discourse Analysis of Accounts of Treatment Experiences. Journal of Community and Applied Psychology, 14, 471-489. doi: $10.1002 /$ casp.804

- Malson, H, Bailey, L, Clarke, S, Treasure, J, Anderson, G \& Kohn, M. (2011). Un/imaginable Future Selves: A Discourse Analysis of In-Patients’ Talk About Recovery from an 'Eating Disorder', European Review of Eating Disorders, 19, 2536: doi: 10.1002/erv.1011.

- Maynard. M \& Purvis. J, editors (1994) Researching Women's Lives from a Feminist Perspective, London: Taylor and Francis.

- McClean, S. (2005). 'The illness is part of the person': discourses of blame, individual responsibility and individuation at a centre for spiritual healing in the North of England, Sociology of Health and Illness, 27: 628-648. doi /10.1111/j.14679566.2005.00459.x/pdf

- Mitchell, A.M \& Bulik, C.M. (2006). Eating disorders and women's health: an update, Journal of Midwifery and Women's Health, 193-201. doi: 10.1016/j.jmwh.2006.01.005

- Morgan, J.F. (1999), Eating Disorders and Reproduction. Australian and New Zealand Journal of Obstetrics and Gynecology, 39: 167-173. doi:10.1111/j.1479828X.1999.tb03364.X 
- Petrakaki, D, Waring, J \& Barber, N. (2014). Technological affordances of risk and blame: the case of an electronic prescription service in England, Sociology of Health and Illness, 36: 703-718. doi: 10.1111/1467-9566.12098.

- Piran, N. (2010). A feminist perspective on risk factor research and on the prevention of eating disorders. Eating disorders: The Journal of Treatment and Prevention, 18 (3), 183-198.

- Potter, J, Wetherell, M. (1987). Discourse and Social Psychology: Beyond Attitudes and Behaviour. London, Sage.

- Ruiter, R.A.C, Abraham, C \& Kok, G. (2001). Scary warnings and rational precautions: A review of the psychology of fear appeals, Psychology and Health, 16 (6): 613-630.

- Sachs, L. (1996) Causality, responsibility and blame - core issues in the cultural construction and subtext of prevention, Sociology of Health and Illness, 18: 632-652. Doi: 10.1111/1467-9566.ep10934515

- Saukko, P. (2008). The Anorexic Self: A personal and Political Analysis of a Diagnostic Discourse. Albany: State University of New York Press.

- Snelling, P.C (2015) Who can blame who for what and how in responsibility for health?, Nursing Philosophy, 16: 3-18. doi: 10.1111/nup.12061

- Szewczuk, E. (2012). Age-related infertility: a tale of two technologies, Sociology of Health and Illness, 34: 429-443. DOI: 10.111/j.1467-9566.2011.01382x.

- Weedon, C. (1987). Feminist Practice and Post Structuralist Theory, Oxford: Basil Blackwell. 
- Wentz, E, Gillberg C [Carina], Gillberg, C [Christopher], \& Rastam, M. (2005). Fertility and history of sexual abuse at 10 year follow-up of adolescent-onset anorexia nervosa. International Journal of Eating Disorders, 37, 294-298. doi: 10.1002/eat.20093

- Wolfe, B.E. (2005). Reproductive Health in women with eating disorders, JOGNN: Clinical issues, March/ April: 255-263. DOI: $10.1177 / 0884217505274595$

- Zerbe Enns, C. (1993) Twenty Years of Feminist Counseling and Therapy: From Naming Biases to Implementing Multifaceted Practice, The Counseling Psychologist, 21: 3-87. DOI: 10.1177/0011000093211001

'In medical terms, someone diagnosed with atypical anorexia fits much of the criteria for anorexia, aside from the very low BMI. 